\title{
Management diversification increases habitat availability for multiple biodiversity indicator species in production forests
}

\author{
R. Duflot $\mathbb{D} \cdot$ K. Eyvindson $(\mathbb{D} \cdot$ M. Mönkkönen $(10)$
}

Received: 31 August 2020/Accepted: 16 November 2021 / Published online: 29 November 2021

(C) The Author(s) 2021

\begin{abstract}
Context Forest biodiversity is closely linked to habitat heterogeneity, while forestry actions often cause habitat homogenization. Alternative approaches to even-aged management were developed to restore habitat heterogeneity at the stand level, but how their application could promote habitat diversity at landscape scale remains uncertain.

Objectives We tested the potential benefit of diversifying management regimes to increase landscapelevel heterogeneity. We hypothesize that different styles of forest management would create a diverse mosaic of forest habitats that would in turn benefit species with various habitat requirements.
\end{abstract}

Supplementary Information The online version contains supplementary material available at https://doi.org/10.1007/ s10980-021-01375-8.

R. Duflot $(\bowtie) \cdot$ K. Eyvindson · M. Mönkkönen

Department of Biological and Environmental Science, University of Jyvaskyla, P.O. Box 35,

FI-40014 Jyvaskyla, Finland

e-mail: duflot.remi@gmail.com

R. Duflot · K. Eyvindson · M. Mönkkönen

School of Resource Wisdom, University of Jyvaskyla,

P.O. Box 35, FI-40014 Jyvaskyla, Finland

\section{K. Eyvindson}

Faculty of Environmental Sciences and Natural Resource Management, Norwegian University of Life Sciences,

P.O. Box 5003, NO-1432 Ås, Norway
Methods Forest stands were simulated under business-as-usual management, set-aside (no management) and 12 alternative management regimes. We created virtual landscapes following diversification scenarios to (i) compare the individual performance of management regimes (no diversification), and (ii) test for the management diversification hypothesis at different levels of set-aside. For each virtual landscape, we evaluated habitat availability of six biodiversity indicator species, multispecies habitat availability, and economic values of production.

Results Each indicator species responded differently to management regimes, with no single regime being optimal for all species at the same time. Management diversification led to a $30 \%$ gain in multispecies habitat availability, relative to business-as-usual management. By selecting a subset of five alternative management regimes with high potential for biodiversity, gains can reach $50 \%$.

Conclusions Various alternative management regimes offer diverse habitats for different biodiversity indicator species. Management diversification can yield large gains in multispecies habitat availability with no or low economic cost, providing a potential cost-effective biodiversity tool if the management regimes are thoughtfully selected.

Keywords Heterogeneity - Biodiversity conservation $\cdot$ Landscape planning $\cdot$ Forest 
management $\cdot$ Sustainable management $\cdot$ Boreal forest $\cdot$ Temperate forest

\section{Introduction}

Landscape heterogeneity, i.e. the variation of ecological conditions in space and time, offers opportunities for ecological communities with various environmental requirements to co-exist at landscape level. Species turnover across spatial gradients (i.e. beta diversity) is considered a determinant of overall diversity of a landscape (i.e. gamma diversity, Tscharntke et al. 2012). In forest landscapes under natural dynamics, heterogeneity is provided and maintained by disturbances at different spatial scales such as forest fires, wind throws, and local-scale gap dynamics (Angelstam 1998; Kuuluvainen 2002, 2009; Bouget and Duelli 2004; Schütz et al. 2016). In contrast, landscapes that have been under intensive human use (production landscape), for instance in the European boreal and temperate forests, experience a simplification (homogenisation) of habitats at stand and landscape scales, threatening forest biodiversity $(\mathrm{Ku}-$ uluvainen 2002; Kuuluvainen and Gauthier 2018). Fire suppression and the use of harvesting cycles (rotation length) shorter than tree life span have drastically reduced natural disturbances, while tree planting and seedling, tree selection and harvesting of timber (clear-felling or partial cuts) results in reduced tree species diversity and absence of important natural disturbance legacies (Bengtsson et al. 2000; Odion and Sarr 2007; Schütz et al. 2016). Consequently, managed forest stands, particularly in the clear-felling systems, lack important habitat features such as large old trees supporting micro-habitats (e.g. cavities) and large amount of standing and downed deadwood (Bouget et al. 2014; Juutilainen et al. 2014; Larrieu et al. 2017). At the landscape scale, forest management modifies the age-class distribution, with a much larger area with early successional stage and a drastic reduction of mature or old forest, as compared to natural forests (Kuuluvainen and Gauthier 2018). In more recently exploited forest landscapes, e.g. in North-American forests, timber extraction may increase heterogeneity by creating open and early stage forest habitats (although perhaps degraded).
However, in the long-term, forestry activities generate stands that are similar to each other, creating landscapes with a narrow range of variation in structure compared to natural forests (Kuuluvainen and Gauthier 2018).

These modifications threaten biodiversity as they depart greatly from the environment in which native forest species have evolved (Kuuluvainen 2009). However, although crucial for maintaining biodiversity, there is a consensus that (i) the current area of protected forest is insufficient to ensure biodiversity protection alone and increasing this proportion would represent high economic loss for forest industry; and, therefore, that (ii) managed forests should contribute to biodiversity protection as well (Kuuluvainen 2009; Gustafsson et al. 2010).

To compensate for the negative impacts production forestry has on the important structures for biodiversity, focus should be placed on alternative management practices that offset the biodiversity loss at a minor loss of merchantable timber. To restore forest habitats (at least partially), alternative management have been designed as alteration of the usual practices (Mönkkönen et al. 2018). The most widely applied alternative is green tree retention, where living and dead single trees, groups of trees, or buffer strips are left uncut at the time of harvest, usually from few percent to $30 \%$ of total timber volume (Gustafsson et al. 2010, 2012). These retained trees increase the structural complexity and amount of deadwood in the harvested stand. Retention seem efficient to increase richness and abundance of various taxa compared to clear-cuts (Fedrowitz et al. 2014). Another form of retention is uneven-aged or continuous cover forestry, where the forest is only partially and selectively harvested to maintain a continuous canopy cover (Pukkala and Gadow 2012). Continuous cover forestry has been shown to increase the density of large trees and benefit indicator species dependant on mature, dense, or mixed tree species forest (Peura et al. 2018). However, the positive effect of continuous cover forestry on saproxylic beetle communities depends on the amount of deadwood left (Gossner et al. 2013). Alternative approaches to increase deadwood volume is to extend the rotation length (i.e. delayed harvest) and to change the regime of thinnings (i.e. intermediate cuts of smallest trees before final harvest), as these result in increased natural tree mortality. Elongated rotation lengths allow trees to grow larger and 
older, increase deadwood volume and proportion of broadleaved trees generating more mixed forests (Roberge et al. 2016; Felton et al. 2017). However, these benefits are mitigated if increased thinning applications are applied (Roberge et al. 2016). In fact, when comparing unthinned stands with regularly thinned stands, amount of deadwood is 5-6 times larger due to self-thinning from natural death of smaller trees (Tikkanen et al. 2012). Even though many of these alternative management regimes have been applied for quite some time, we do not know how effective they are in providing sufficient landscape heterogeneity for biodiversity, and what combination of alternative management regimes together with setting aside forests from forestry would be required.

Given the diversity of life forms in forests, and that alternative management regimes are only partial reproduction of natural disturbances, it is unlikely that any single forest management regime would be able to support all forest-associated species. One particular management regime can be tailored to introduce heterogeneity at the stand level increasing local diversity. However, if systematically applied at landscape scale it would rather homogenize habitats and reduce beta diversity (e.g. continuous cover forestry, Schall et al. 2018). Some studies suggested optimal planning for multiple species groups (and multiple ecosystem services) should include several management regimes (Redon et al. 2014; Mönkkönen et al. 2014; Triviño et al. 2017; Eyvindson et al. 2018). This is in line with theoretical work on sustainable forest management, whose objective should be to produce irregularity, using a diversity of cutting options in combination (Schütz et al. 2016). Although not formally tested, it is assumed that more variation in management regimes is needed. Using a range of alternative regime should provide best opportunities to generate heterogeneous landscapes and offer habitats to a range of species groups with various ecological requirements, thus increasing beta diversity (Mönkkönen et al. 2018; Nolet et al. 2018).

Alternative management regimes are designed to promote biodiversity with limited economic costs (Pukkala and Gadow 2012; Gustafsson et al. 2012; Tikkanen et al. 2012). Some of these regimes focus on delaying or limiting timber extraction, so they remain economically productive, however they tend to produce habitats of lower quality compared to untouched forests (Gustafsson et al. 2010; Gossner et al. 2013; Fedrowitz et al. 2014; Peura et al. 2018). Setting aside forests, where no management is allowed can therefore be more effective to protect biodiversity, but at a much higher economic cost. While earlier studies have suggested management diversification can maintain biodiversity in production forest landscapes, no earlier study has directly compared the cost-efficiency between increasing set-asides vs. utilizing a diverse set of alternative management regimes that aim at reconciling production with biodiversity conservation.

Our objective was to explore the effect of management diversity, i.e. combining various management regimes at a landscape scale, in terms of habitat diversity, availability and stability over time, and to estimate the associated economic costs. A representative Finnish forest landscape was simulated under business-as-usual management (Business-As-Usual [BAU], where the rotation consists of planting, two to three thinning operations followed by clear-felling harvesting with 60-80 years rotation length), set-aside (no management) and 12 alternative management regimes. We created virtual landscapes following diversification scenarios to (i) compare the individual performance and potential complementarity of management regimes (no diversification), and (ii) test for the management diversification hypothesis (increasing number of management regimes included and at different levels of set-aside). For each virtual landscape, we evaluated habitat availability of six biodiversity indicator species associated with different forest habitat types and representative of overall biodiversity. We also measured a combined multispecies habitat availability, its variation over time, and economic values of timber production.

\section{Method}

First, the capacity of management regimes to provide suitable habitats and their potential complementarity was assessed by evaluating biodiversity in landscapes entirely (i.e. all stands) managed with a single management regime (no diversification). Habitat availability for the six biodiversity indicator species 
and a combined multispecies habitat availability (see below) were calculated for these "pure" landscapes. Second, we explored diversification scenarios that included an increasing number of management regimes. This was done for various levels of set-aside (i.e. $0,10,25,50$, and $80 \%$ of total forest area) and for two sets of alternative management regimes: (i) all 12 alternative management regimes (ii) only a subset of five management regimes that depart the most from business-as-usual management (Table 1). We looked at how the diversification scenarios affected multispecies habitat availability and its variability over time. Finally, we compared the economic costs and biodiversity benefits of management diversification vs. increased proportion of set-aside.
Forest growth simulation and management regimes

The study area is a watershed consisting of 413 forest stands covering 491.8 ha (average stand area $=1.2$ ha) and is representative of Finnish production forest landscapes. A forest stand is the management unit of forestry practices with consistent within-stand structural characteristics in terms of site type (e.g. soil fertility), tree age, and species composition. Forest stand characteristics used as input variables for the simulator were obtained from the Finnish Forest Centre (www.metsaan.fi) and include stand-level variables (geographic location, size, soil type, site type, drainage status) and stratum level variables (tree

Table 1 Description of the reference management (BAU), set-aside and the 12 alternative management regimes used in the simulations, and average harvested volume they generate over the 100-year simulation period

\begin{tabular}{|c|c|c|c|c|c|c|c|}
\hline $\begin{array}{l}\text { Management } \\
\text { regime }\end{array}$ & Abbreviation & Regeneration & Harvest & $\begin{array}{l}\text { Thinning from } \\
\text { below }\end{array}$ & $\begin{array}{l}\text { Retention } \\
\text { (/ha) }\end{array}$ & $\begin{array}{l}\text { Rotation } \\
\text { length } \\
\text { or harvest } \\
\text { threshold }\end{array}$ & $\begin{array}{l}\text { Harvested } \\
\text { volumes } \\
\left(\mathrm{m}^{3} / \mathrm{ha}\right)\end{array}$ \\
\hline Business-As-Usual & BAU & Planted & Clear-cut & After 1st harvest & 10 trees & $60-80$ years & 648.7 \\
\hline $\begin{array}{l}\text { BAU with extended } \\
\text { rotation }(+10 y)\end{array}$ & BAU_10 & Planted & Clear-cut & After 1st harvest & 10 trees & 70-90 years & 575.5 \\
\hline $\begin{array}{l}\text { BAU with extended } \\
\text { rotation }(+30 y)^{*}\end{array}$ & BAU_30 & Planted & Clear-cut & After 1st harvest & 10 trees & $90-110$ years & 512.8 \\
\hline BAU with thinning & BAUwT & Planted & Clear-cut & Yes & 10 trees & $60-80$ years & 636.2 \\
\hline $\begin{array}{l}\text { BAU with thinning, } \\
+10 \mathrm{y}\end{array}$ & BAUwT_10 & Planted & Clear-cut & Yes & 10 trees & 70-90 years & 566.7 \\
\hline $\begin{array}{l}\text { BAU with thinning, } \\
+30 y^{*}\end{array}$ & BAUwT_30 & Planted & Clear-cut & Yes & 10 trees & $90-110$ years & 483.6 \\
\hline $\begin{array}{l}\text { BAU with higher tree } \\
\text { retention }\end{array}$ & BAU_wGTR & Planted & Clear-cut & Yes & 30 trees & $60-80$ years & 634.8 \\
\hline $\begin{array}{l}\text { BAU without thinning, } \\
-20 \mathrm{y}\end{array}$ & BAU_woT_m20 & Planted & Clear-cut & No & 10 trees & 40-60 years & 698.4 \\
\hline BAU without thinning* & BAU_woT & Planted & Clear-cut & No & 10 trees & $60-80$ years & 582.8 \\
\hline $\begin{array}{l}\text { BAU without thinning, } \\
+10 y^{*}\end{array}$ & BAU_woT_10 & Planted & Clear-cut & No & 10 trees & 70-90 years & 458.2 \\
\hline $\begin{array}{l}\text { Continuous cover } \\
\text { forestry }(\mathrm{CCF})\end{array}$ & CCF_2 & Natural & From above & No & $\begin{array}{l}\text { Min } \mathrm{BA}= \\
\quad 9-10 \mathrm{~m}^{2}\end{array}$ & $\begin{array}{l}\mathrm{BA}=16-22 \\
\mathrm{~m}^{2} / \mathrm{ha}\end{array}$ & 600.2 \\
\hline $\begin{array}{l}\text { CCF, reduced harvest } \\
\text { threshold }\end{array}$ & CCF_1 & Natural & From above & No & $\begin{array}{l}\operatorname{Min} \mathrm{BA}= \\
9-10 \mathrm{~m}^{2}\end{array}$ & $\begin{array}{l}\mathrm{BA}=14-20 \\
\mathrm{~m}^{2} / \mathrm{ha}\end{array}$ & 603.9 \\
\hline $\begin{array}{l}\text { CCF, increased harvest } \\
\text { threshold* }\end{array}$ & CCF_3 & Natural & From above & No & $\begin{array}{l}\operatorname{Min} \mathrm{BA}= \\
9-10 \mathrm{~m}^{2}\end{array}$ & $\begin{array}{l}\mathrm{BA}=18-24 \\
\mathrm{~m}^{2} / \mathrm{ha}\end{array}$ & 557.5 \\
\hline $\begin{array}{l}\text { Set-aside: no } \\
\text { management }\end{array}$ & SA & Natural & No & No & - & - & - \\
\hline
\end{tabular}

The range of values provided for rotation length, harvest threshold and retention were applied to forest stand depending on site productivity classes. Basal area (BA) requirements increased and rotation length decreased with higher productivity

*The five management regimes that were considered most different from BAU and used in the diversification scenarios with a reduced number of management regimes 
species, number of stems, height, diameter, age). We used the forest growth simulator SIMO (Rasinmäki et al. 2009) to simulate forest development 100 years into the future with twenty 5-year time steps and for 14 management regimes.

Management regimes, i.e. sets of silvicultural operational rules applied at stand level, include setaside (no management), BAU, which is the currently recommended by the state-owned advisory Forestry Development Centre Tapio, and dominant management regime in Finland, and twelve alternative management regimes (Table 1; Äijälä et al. 2014). All of these alternative management regimes represent different combinations of forestry practices that are currently discussed to promote biodiversity: extended rotation (i.e. delayed harvest), absence of thinning, retention of living trees at harvest, no clear-felling (Table 1; Äijälä et al. 2014). Each stand was simulated under a maximum of 14 management regimes. Some management regimes could not be applied to all stands depending on their initial conditions, particularly those that required thinning before harvest (BAUwT, Table 1) cannot be applied on initially mature stands. More details on how the management regimes were implemented in the simulation can be found in Eyvindson et al. (2018, 2021) and Peura et al. (2018).

In addition to forest structure information, we used the economic value of each stand for each management regimes provided by SIMO. Estimation of economic value was based on planting costs (in rotation forestry regimes), harvested timber volume, timber size category (pulpwood vs. sawlog), tree species, and harvesting type (harvesting from above provides lower income than clear-felling). Operational costs following harvest were the same for all rotation forestry management regimes that is between 1460 and $1760 € / \mathrm{ha}$, including mounding (220 €/ha), fertilization (260€/ha), early tending (220€/ha), planting (510 €/ha for pine, $627 € /$ ha for spruce, and $813 € /$ ha for birch), and tending of seedling stand ( 250 $€ /$ ha). Timber harvest costs were accounted for within a fixed price for timber, as road construction is typically not needed in Finland. Additional costs for timber extraction in CCF regimes, i.e. higher transportation costs for the same amount of timber, was accounted for using reduced prices: $10 \%$ reduction of for logs and 15-25\% reduction for pulp (depending on tree species). We calculated for each stand and each management regimes the Net Present Value that is the sum of net income provided at each time step and the value of standing tree at the end of the simulation period (i.e. at 100 years), using a discount rate of $3 \%$ :

$N P V_{i, j}=\sum_{k=1}^{20} \frac{\text { Net income }_{i, j, k}}{1.03^{\text {year }, k}}+\frac{P V_{i, j, 100 y}}{1.03^{100}}$

wherein, $N P V_{i, j}$ is the Net Present Value of stand $i$ under management regime $j$; Net income $e_{i, j, k}$ is the net income at time step $k$; and $P V_{i, j, 100 y}$ is the present value of standing trees at the end of last time period (i.e. 100 years, Pukkala 2005). 1.03 account for a $3 \%$ discount rate; year, $k$ is the mid-year of time-step $k$. This is a standard discount rate commonly applied in European countries for evaluating social policies or development projects (Johansson and Kriström 2012). We calculated the landscape-level NPV as the sum of NPV values of individual stands.

\section{Diversification scenarios and virtual landscapes}

BAU and set-aside were considered particular cases of management. BAU is the current dominant management regime in the Finnish landscapes and is unlikely to disappear. Therefore, BAU was always included in the diversification scenarios and served as a reference to evaluate the benefit of management diversification for biodiversity. Set-aside is a no-management regime applied to a forest stand that was previously managed (i.e. put aside from forestry operations). It causes high economic loss (no income), and has higher potential for biodiversity than other alternative management regimes (Mönkkönen et al. 2014).

We define a diversification scenario as a particular combination of BAU, set-aside, and alternative management regimes at the landscape scale. Scenarios varied in two dimensions: they included (i) an increasing number of alternative management regimes and (ii) an increasing proportion of set-aside. Scenarios with increasing number of alternative management regimes (n) were created using all possible combination of alternative management regimes. We tested the 4,095 or 31 possible combination with twelve or five alternative management regimes $(\mathrm{K})$ included respectively; as the total number of combination $\left(C_{T}\right)$ equals:

$C_{n}=\frac{K !}{n !(K-n) !}$ 


$$
C_{T}=\sum_{n \in[1, K]} C_{n}
$$

where $K$ is the total number of alternative management regimes (12 or 5), $n$ is the number of management regimes included in a particular diversification scenario, $C_{n}$ is the number of combinations when $n$ of the $K$ management regimes are used, and $C_{T}$ the total number of combinations.

We then replicated each scenario by creating virtual landscapes, defined as a random implementation of a diversification scenario to the study landscape. For each scenario we created virtual landscapes, where management regimes were randomly assigned to individual forest stands. Because the assignment is random with an equal probability, the resulting landscapes always contained equal shares of the management regimes included, e.g. four management regimes led to $25 \%$ area for each, excluding the setaside area that always had a fixed proportion. This allows testing the effect of number of management regimes independently from their relative proportions in the landscape.

About 5000 virtual landscapes were created for each number of management regimes, equally distributed between the combinations of $\mathrm{n}$ management regimes. We aimed to have a least 5000 virtual landscapes for each level of $n$ but as the number of combinations differ, the exact number of replicates slightly differ. For instance, there are 495 combinations of four management regimes out of 12 (Eq. 2); we created 11 virtual landscapes for each combination, leading to 5445 replicates at $n=4$. This was done so that the number of virtual landscapes is regular, and the variability of biodiversity outcome equally assessed, along the gradient of management diversification. The entire process was repeated for the five levels of set-aside: $0,10,25,50$, and $80 \%$ of total forest area.

\section{Biodiversity assessment}

We estimated gamma diversity using six biodiversity indicator species that represent a wide range of habitat requirements in boreal forests (Mönkkönen et al. 2014). The focal species are all considered either umbrella or indicator species. Umbrella species either have large habitat needs or other requirements whose conservation results in many other species being conserved at the ecosystem or landscape level, while indicator species status provides information on the overall condition of the ecosystem and of other species in that ecosystem. Thus, we assert that in summary they provide information of the status of biodiversity at landscape scale more generally. For each species we used an expert-based habitat suitability model (HSM) that relate directly to forest stand characteristics, which are well described in the output of the SIMO simulator (Mönkkönen et al. 2014). (i) Western capercaillie (Tetrao urogallus) is considered an umbrella species whose presence indicates suitable habitat for 15 other mammal and bird species with diverse ecology and habitat requirements (Pakkala et al. 2003). Western capercaillie is associated with pine-dominated mixed coniferous forest, with several vegetation layers (Miettinen 2009). HSM is based on volume of pine and spruce, and tree density. (ii) Three-toed woodpecker (Picoides tridactylus) has been suggested an indicator of overall bird species richness (Pakkala 2012). Its habitat is dense mature conifer-dominated forests that contains high amount of fresh deadwood (Pakkala et al. 2002). HSM is based on basal area of recently died trees and total tree volume. (iii) Siberian flying squirrel (Pteromys Volans) is included as vulnerable species in the red list of Finland (Hyvärinen et al. 2019), and is protected by the Habitats Directive Annex IV of European Union (92/43/EEC). It prefers spruce-dominated old dense forests, mixed with deciduous trees (Hokkanen et al. 1982; Hanski et al. 2000). It is considered an umbrella species for a variety of wood dependent species e.g. polypores, epiphytic lichens and beetles (Hurme et al. 2008). HSM is based on volume and proportion of spruce and volume of deciduous trees (iv) Hazel grouse (Tetrates bonasia) is included as vulnerable species in the red list of Finland (Hyvärinen et al. 2019) and prefers mixed conifer-deciduous forests. It is suggested to be a good indicator of adequate level of deciduous trees in boreal forest (Angelstam 1992), and thus, providing an umbrella for boreal species dependent on living deciduous trees. HSM is based on forest age and proportion of spruce and deciduous trees (v) Long-tailed tit (Aegithalos caudatus) and (vi) Lesser-spotted woodpecker (Dendrocopos minor) are birds that depend on deciduous 
trees. Long-tailed tit prefers stands with large alder (Alnus spp.) and birch trees (Betula spp., Jansson and Angelstam 1999), while the Lesser-spotted woodpecker is dependent on high amount of deciduous snags (Angelstam et al. 2004). Both species are good indicators of bird richness in deciduous forests in Northern Europe (Roberge and Angelstam 2006). HSM of Long-tailed tit is based on forest age, total basal area, and proportion of deciduous trees, while HSM of Lesser-spotted woodpecker is based on basal area of recently died deciduous trees and age of deciduous living trees.

For every virtual landscape, we assessed the amount of available habitat for these six biodiversity indicator species. Forest stands with a habitat suitability index (HSI) greater than 0.7 were considered as suitable habitat. Habitat availability was defined as the proportion area of suitable stands relative to total forest area (in \%) and calculated for each indicator species and each time-step. Landscape-level biodiversity potential was estimated using a multispecies habitat availability, defined as the average habitat availability across the six biodiversity indicator species. We tested several normalization methods prior to calculating the average across species (not shown), but this did not affect the results. Finally, habitat availability measures were averaged over the whole simulation period. The temporal variability was evaluated by (i) looking at the evolution of multispecies habitat availability over time and (ii) calculating its standard deviation over the whole simulation period.

The obtained multispecies habitat availability values were also expressed as a relative gain (\%) from the reference scenarios, i.e. a landscapes entirely manage with BAU, except the proportion randomly assigned to set-aside $(\mathrm{n}=0)$. We did not expect the biodiversity potential to increase linearly with increasing number of management regimes but to exhibit saturation, i.e. reduced benefit of increasing management diversity at high level. Hence, we fitted a log-transformed linear regression. As this is a simulation-based analysis, there are no meaningful statistical hypotheses to be tested, however the strength of effect can be assessed and compared using the slope of the fitted curves (White et al. 2014).

\section{Results}

Independent suitability of alternative management regimes

Set-aside was, by far, the management regime that provided highest habitat availability for the Western capercaillie and Siberian flying squirrel (Fig. 1a, e). Set-aside was also the best management regime for the Lesser-spotted woodpecker. Although set-aside was not the management regime that provided highest habitat availability, it was still providing high level of suitable habitat for the Hazel grouse, the Long-tailed tit, and the Three-toed woodpecker. Consequently, set-aside was on average providing the highest multispecies habitat availability. Beside set-aside, the Western capercaillie, the Long-tailed tit and the Siberian flying squirrel benefited from extended rotation. The continuous cover forestry regimes were the best for the Long-tailed tit and provided habitats to the Hazel grouse and the Lesser-spotted woodpecker. Extended rotation with thinning provided the best habitat to the Hazel grouse, while, on the contrary, absence of thinning was best for the Three-toed woodpecker. On average, alternative management regimes performed better than BAU in providing multispecies habitat availability, except compulsory thinning. Delayed harvest (i.e. extended rotation) always provided higher habitat availability. Green tree retention had limited multispecies value and was not the best management regimes for any of the biodiversity indicator species. However, the addition of green tree retention often performed better than BAU, especially for the Three-toed woodpecker. The five alternative management regimes that depart the most from the recommended management (businessas-usual, see Table 1) provided the highest multispecies habitat availability after SA (Fig. 1g). The range of habitat availability value differed between the indicator species, highlighting the differences in specificity of habitat considered in the habitat suitability models. For instance, the Western capercaillie model focus on very specific sites (male lekking habitat), hence lower values of habitat availability were observed (Fig. 1a). 
(a) Capercaillie

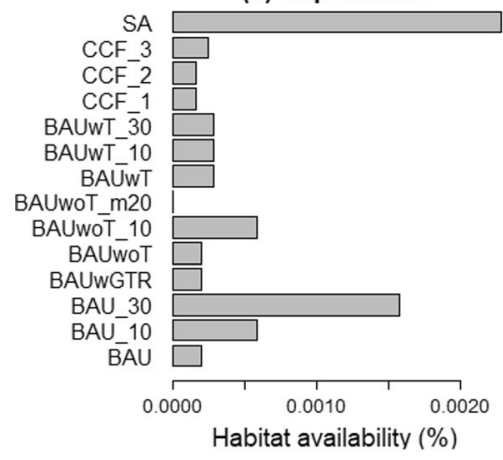

(d) Long-tailed tit

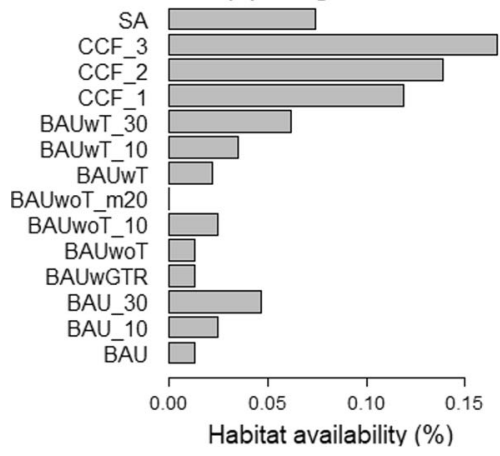

(g) Multispecies

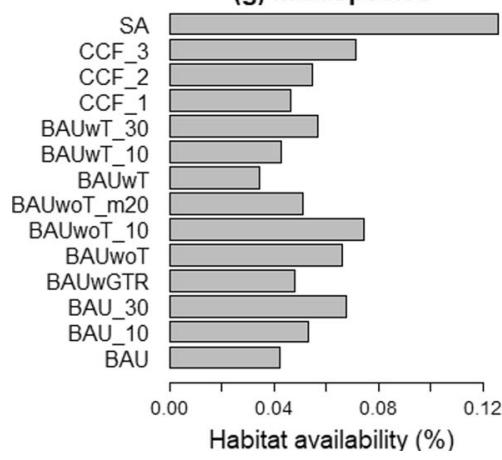

Fig. 1 Habitat availability (percentage of total forest area) of the six biodiversity indicator species $(\mathbf{a}-\mathbf{f})$ and multispecies habitat availability (average, $\mathbf{g}$ ) in landscape entirely (i.e. all

Effect of management diversification on multispecies habitat availability

Management diversification resulted in gain of multispecies habitat availability compared to the reference scenarios using only BAU, for both cases, i.e. when all 12 and only the subset of five alternative management regimes were included (Figs. 2, 3). However, the positive effect of management diversification (b) Hazel grouse
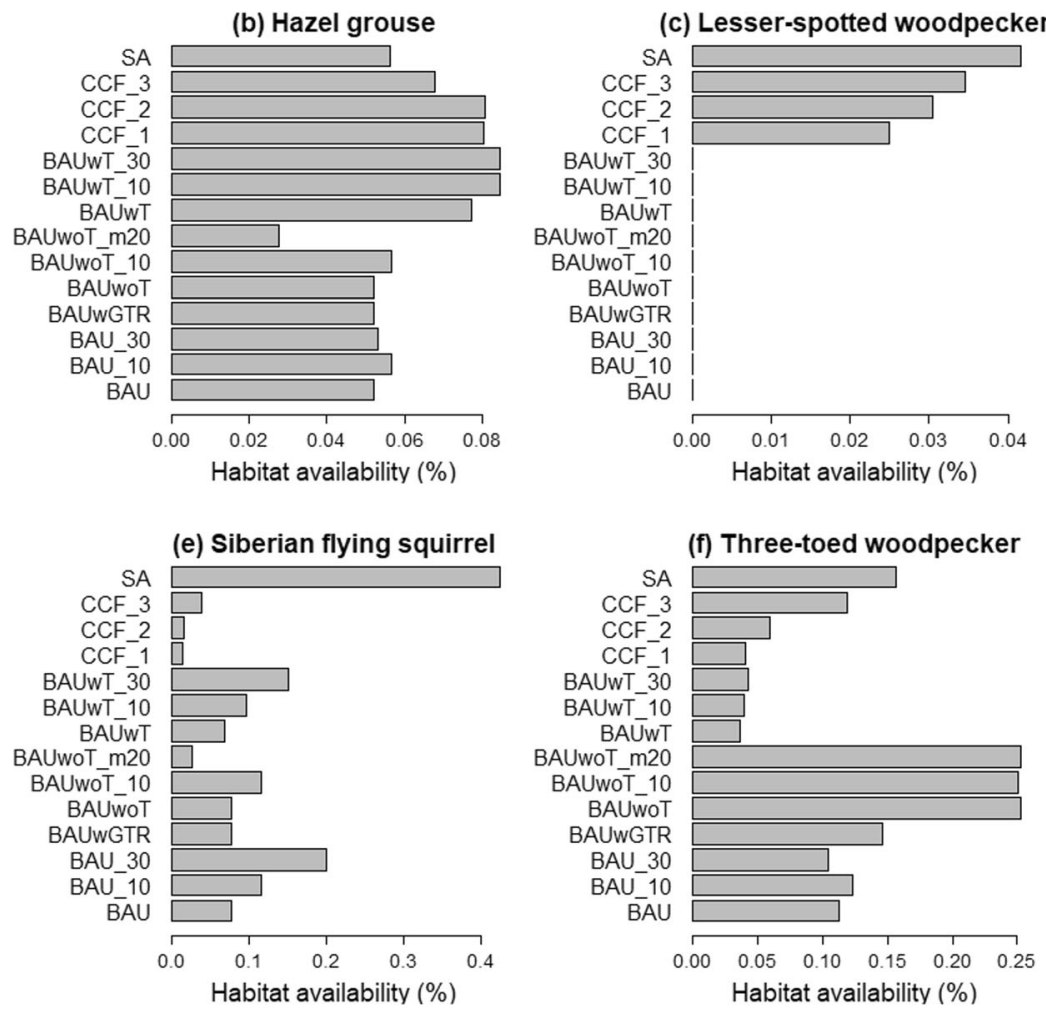

stands) managed using a single management regime. Habitat suitability was defined as forest stands with HSI $>0.7$. See Table 1 for a list of the management regimes and abbreviations

vanished with increasing proportion of set-aside, as shown by the decreasing slope of log-regressions (Figs. 2, 3). At higher than $50 \%$ proportion of setaside, the effect of diversification was close to zero. Although diversification effect disappeared at high proportion of set-aside, the multispecies habitat availability considerably increased with increasing proportion of set asides (Fig. 5a). On average, the absolute multispecies habitat availability doubled 


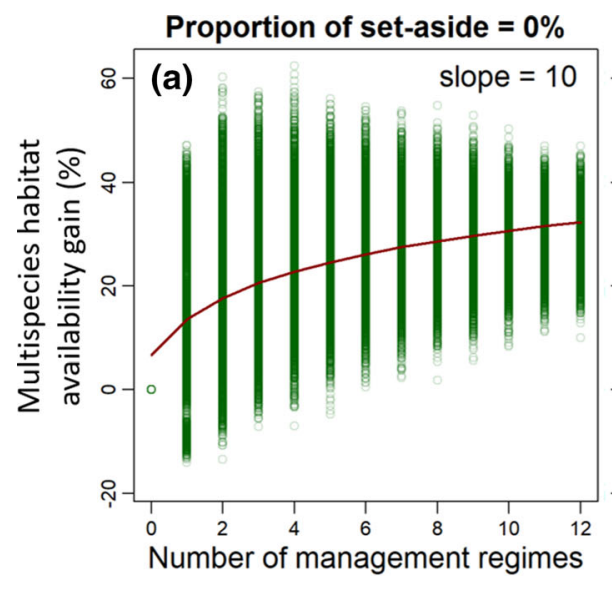

Proportion of set-aside $=\mathbf{2 5 \%}$

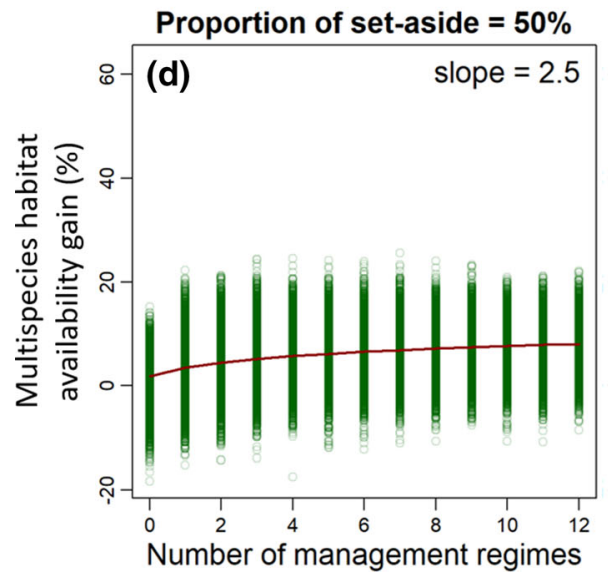

Fig. 2 Multispecies habitat availability gain (\%) as a function of the number of management regimes included, using 12 alternative management regimes and BAU (see Table 1), for scenarios with increasing proportion of set-aside $(\mathbf{a}-\mathbf{e})$. Red line indicates predicted value for a logarithmic relationship (slope $=$

from 4 to $8 \%$ of the forest area when set-aside proportion increased from 0 to $50 \%$, for the reference scenarios $(\mathrm{n}=0)$.

The observed benefit of management diversification was stronger when only the subset of five alternative management regimes were included (Fig. 3), as indicated by steeper slopes of log-regressions. For instance, at $0 \%$ proportion of set-aside, the relative gain in multispecies habitat availability with management diversification was $32 \%$ with all 12 management regimes included, and $54 \%$ with the subset of five management regimes (Fig. 5b); considering relative gains at maximum number of management regimes $(\mathrm{n}=12$ or 5$)$.

Results showed a high variability depending on the random assignment of management regimes to stands.


regression coefficient). The gain was calculated relative to the reference scenario $(n=0)$, that is a landscape entirely manage with BAU, except the proportion randomly assigned to setaside. (Color figure online)

At $0 \%$ proportion of set-aside, using the 12 alternative management regimes, multispecies habitat availability gain ranged from nearly $-20 \%$ (habitat loss) up to + $60 \%$. The maximal gain was then obtained at $\mathrm{n}=2-4$ (Fig. 2). When only the subset of five alternative management regimes were included, the results varied less, and the introduction of alternative management regimes $(n>0)$ always resulted in habitat gain, at $0 \%$ proportion of set-aside (Fig. 3). Even for the reference scenarios without diversification $(\mathrm{n}=0)$, habitat availability varied depending on how the stands allocated to set-aside where chosen. 

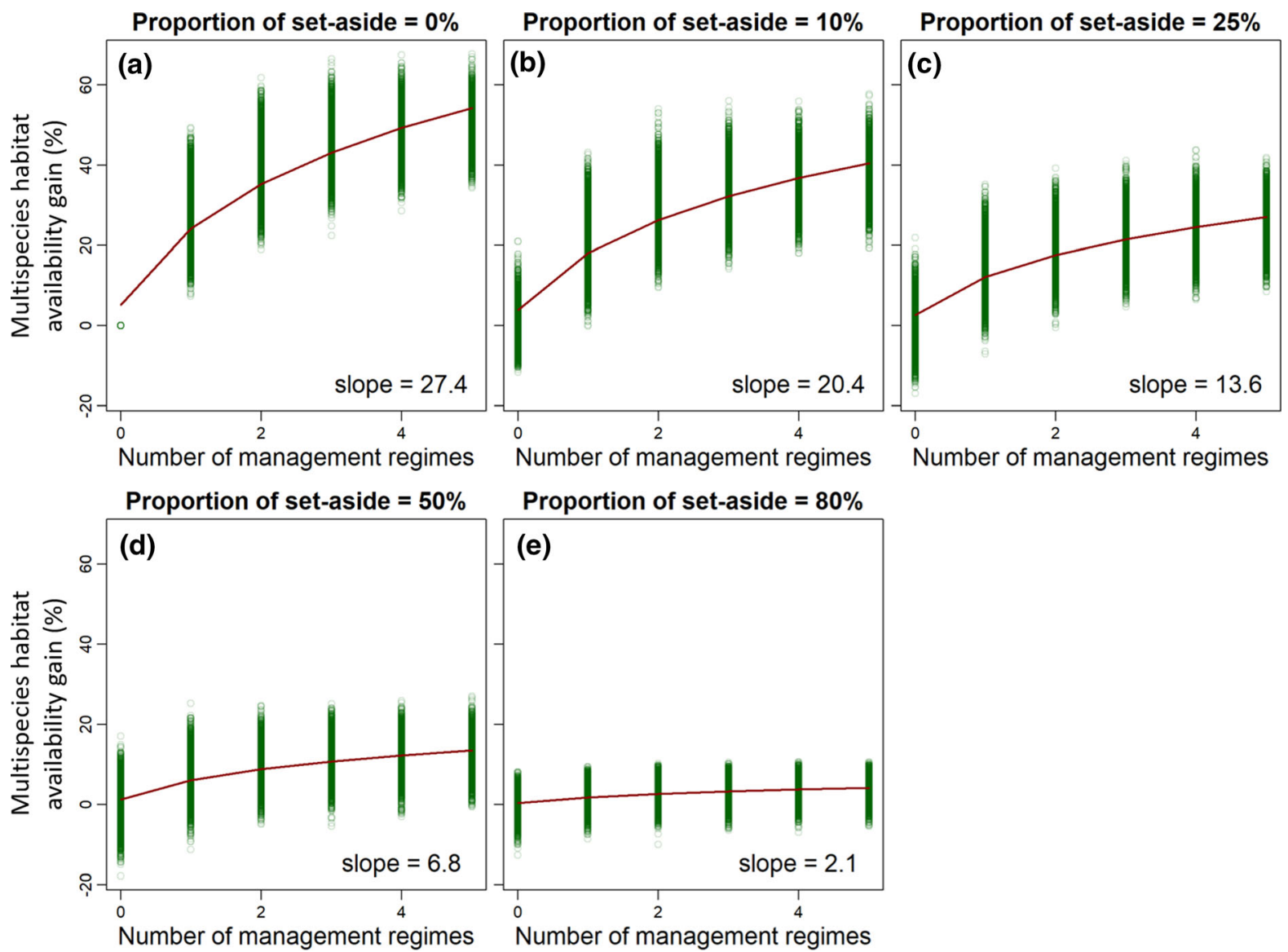

Fig. 3 Multispecies habitat availability gain (\%) as a function of the number of management regimes included, using the five alternative management regimes that depart the most from business-as-usual management in addition to BAU (see Table 1), for scenarios with increasing proportion of set-aside

Temporal variability of multispecies habitat availability

Multispecies habitat availability steadily increased in the beginning of the simulated period, reaching a peak in about 20 years, followed by a steep or smooth decline, depending on diversification scenario (Fig. 4). This general temporal pattern depicts a large variability over time between up to $10 \%$ of the forest as suitable habitats (with $25 \%$ of set-aside), down to close to zero in the case of the reference scenario (BAU), towards the end of the simulated period. Management diversification reduced the variability of multispecies habitat availability over time (see results on standard deviation in Supplementary Material S1, S2). Again, the effect was slightly stronger when (a-e). Red line indicates predicted value for a logarithmic relationship $($ slope $=$ regression coefficient). The gain was calculated relative to the reference scenario $(n=0)$, that is a landscape entirely manage with BAU, except the proportion randomly assigned to set-aside. (Color figure online)

selecting only the subset of five management regimes and vanished with increasing proportion of set-aside.

Management diversity prolonged the peak of habitat availability between 20 and 40 years from initial time and reduced the decline towards the end of the simulated period (Fig. 4a). Selecting a subset of five alternative management regimes did not affect much the temporal pattern in habitat availability but rather the level of habitat availability (Fig. 4b). Increasing proportion of set-aside had similar effects (Fig. 4c, d). Both dimensions of diversification seemed to prevent the multispecies habitat availability to drop below $2.5 \%$ of total forest area (Fig. 4c, d). 

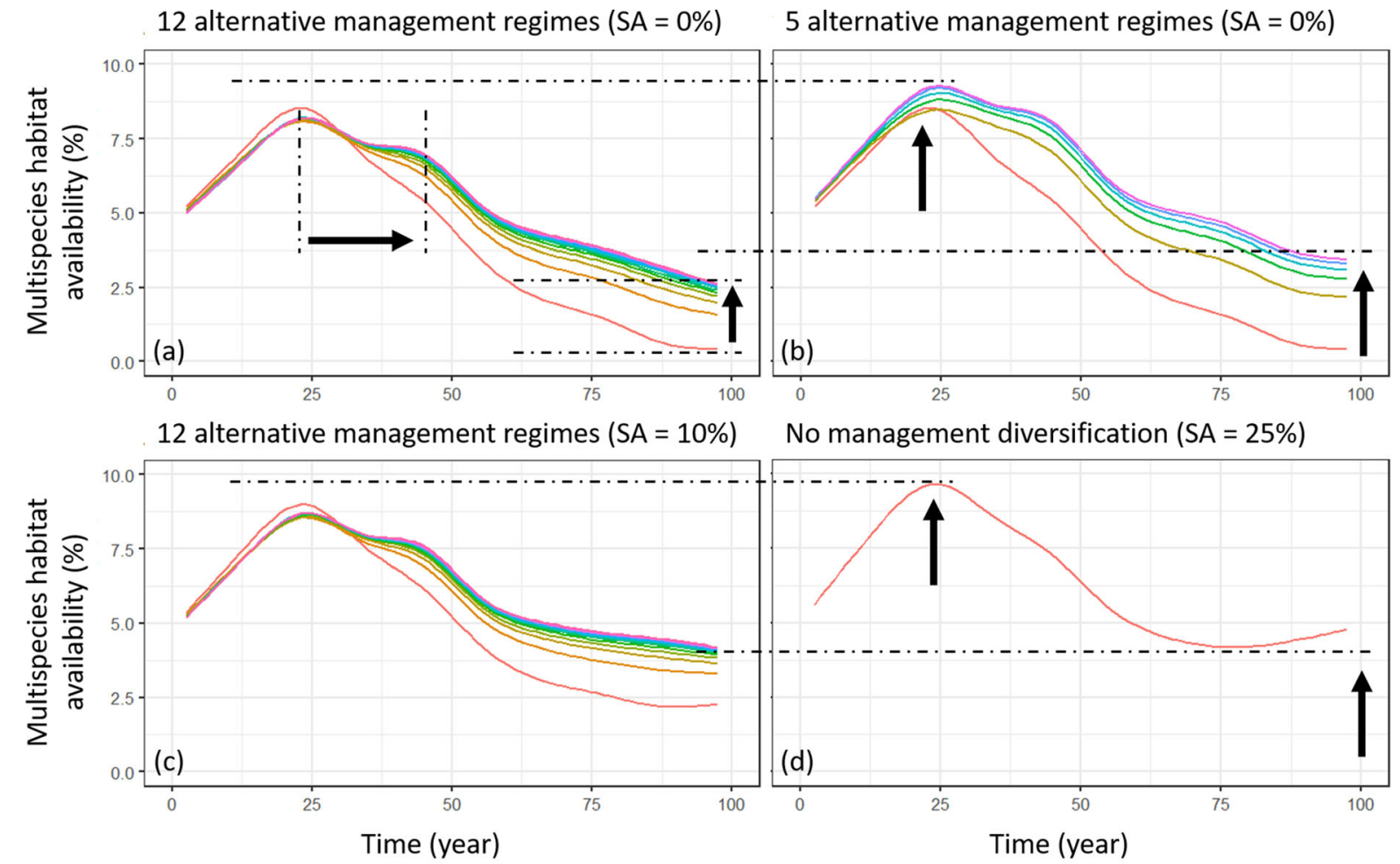

No management diversification $(S A=25 \%)$

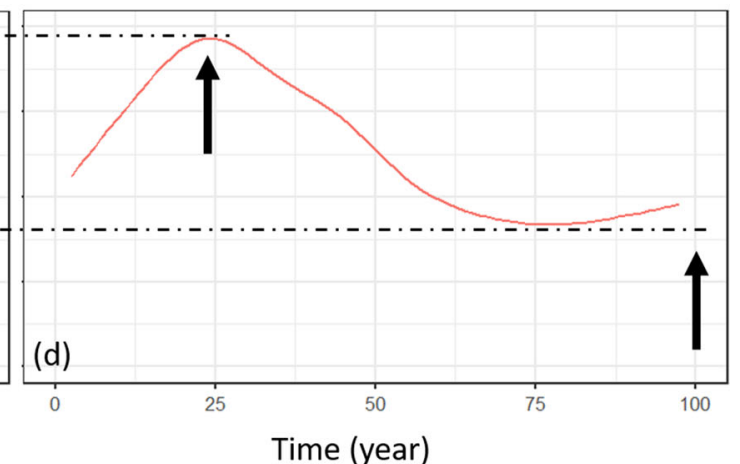

Number of management regimes

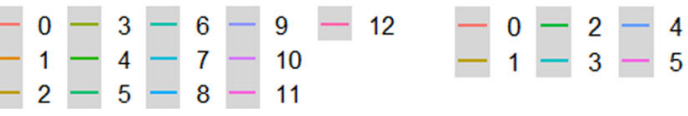

Fig. 4 Multispecies habitat availability (percentage of total forest area) across the 20 studied time-steps for a selection of diversification scenarios (a-d). Red lines indicate the references scenarios (BAU). Black arrows and dashed lines indicate the effect of (a) management diversification using 12 alternative management regimes without set-aside, $\mathbf{a}-\mathbf{b}$ selecting the five

\section{Cost effectiveness of management diversification}

Our results illustrate the high economic cost of setaside, as NPV decreases dramatically with increasing proportion of set aside (Fig. 5). For example, when only BAU management was used, there was a $71 \%$ decrease in NPV with the increase in the proportion of set-aside from 0 to $80 \%$ (from $7.8 \mathrm{k} € /$ ha to $2.2 \mathrm{k} € / \mathrm{ha}$ ). It is notable that management diversification using all 12 management regimes yielded gains in multispecies with no or low cost while management diversification using the subset of five management regimes incurred larger costs. For example, we found $<1 \%$ economic cost of diversification with the 12 alternative management regimes, while increasing habitat availability from 8 to $32 \%$ on average relative to reference scenarios, at $50-0 \%$ of set aside respectively (Fig. 5 b). alternative management regimes that depart the most from business-as-usual, instead of 12 , $\mathbf{c}-\mathbf{d}$ increasing the proportion of set-aside. Coloured lines illustrate predicted generalized additive models, across all replicates. Time is the mid-year of the 5-year time-steps. See Table 1 for a list of the management regimes. (Color figure online)

In contrast, diversification using the subset of five alternative management regimes lead to 10 to $8 \%$ loss in NPV while increasing the relative habitat availability on average $14-54 \%$, at $50-0 \%$ of set aside respectively (Fig. 5b).

The multispecies habitat availability was about at the same level (above 6\% of forest area) for scenarios with no set-aside and diversification with the subset of five alternative management regimes, and $10 \%$ setaside with the 12 alternative management regimes. Also, NPV was about the same for these two scenarios (about $7 \mathrm{k} € / \mathrm{ha}$ ). Further, these two scenarios led to similar multispecies habitat availability as the reference scenario with only BAU management and $25 \%$ set-aside, but that latter scenario had much lower NPV (Fig. 5a). 

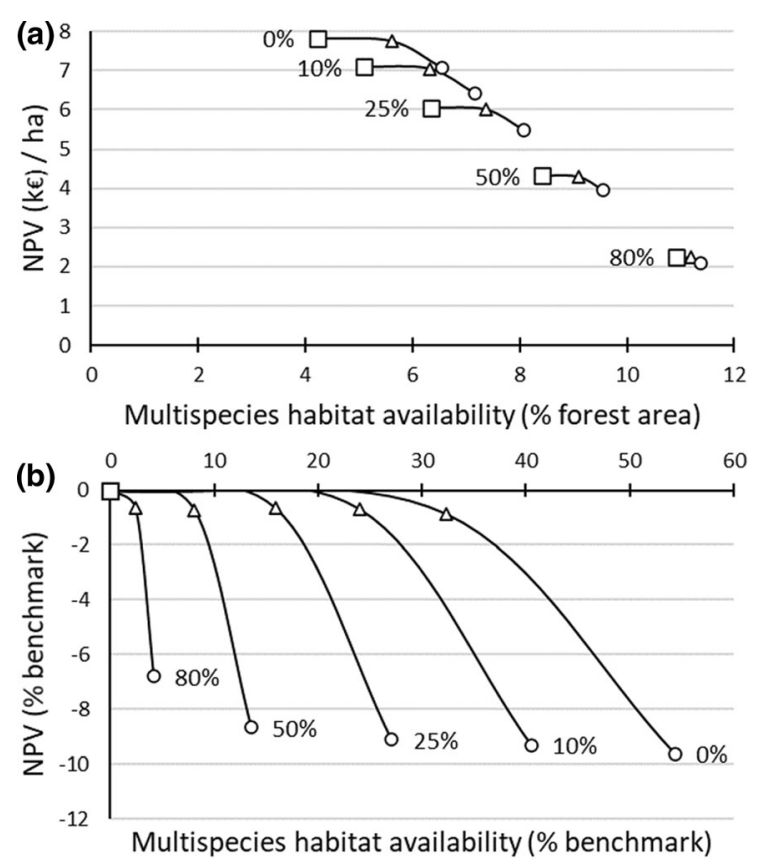

Fig. 5 Cost-efficiency analysis of the reference scenarios with only BAU and the most diversified scenarios at various levels of set-aside (0-80\%), in absolute values (a) and in relative terms compared with the reference (b). Cost-efficiency was assessed by looking at forest Net Present Values ( $\mathrm{k} / \mathrm{ha}$ ) relative to multispecies habitat availability. Squares: reference scenarios (only BAU); triangles: maximum diversification with 12 alternative management regimes; circles: maximum diversification with the subset of five alternative management regimes that depart the most from business-as-usual management. See Table 1 for a list of the management regimes

\section{Discussion}

Management diversification using alternative management regimes resulted in increased habitat availability for the biodiversity indicator species. Our results showed gains in multispecies habitat availability, up to $50 \%$, compared to the reference scenarios using only BAU management, i.e. the currently recommended management practice. Management diversity was efficient at low levels of set-aside (stands with no management), but the beneficial effect vanished at higher levels (at about 50\% set-aside). This is because of the superiority of set-aside in providing habitats for multiple species over other alternative management regimes. A high level of setaside also means lower area for production forests and observed improvements by management diversification are small relative to what is provided by set-aside.
However, it is unlikely that such a high proportion of unmanaged forests is established (e.g. current level in southern Finland is 5\%; LUKE, 2019). Management diversity is therefore a meaningful management policy that would greatly increase habitat availability for a diversity of forest species.

The temporal pattern of multispecies habitat availability showed that the positive effects of management diversity require some time (several decades) to become evident. This is quite expected due to relatively slow forest dynamics and ecosystem responses to changes in management. Such results suggest that practitioners should not expect rapid landscape-level improvements in biodiversity when management diversifies, and that existing suitable habitat patches in the landscape are valuable to keep intact. Still, management diversification seemed to reduce the variability in time of habitat availability, most likely because of extended habitat longevity due to delayed harvests. However, the main temporal pattern, reflecting the initial unbalanced stand age distribution of the studied landscape (Supplementary Material S3), was not altered and management diversification alone could not be prevented the decline in habitat towards the end of the simulated period.

Our results also highlight the importance of careful landscape planning, as a random assignment of management regimes to forest stands resulted in a very high variability, hence uncertain effect towards the change in habitat availability. Management diversification will be more efficient if alternative management regimes are carefully selected. In our case, choosing a subset of five alternative management regimes that depart the most from business-as-usual increased habitat availability up to $54 \%$, while including all 12 alternative management reached only $32 \%$ (on average). Also, focusing on the best alternative management decreased uncertainty. Many cases of diversification with the 12 alternative management regimes did not lead to any increase in habitat availability, i.e. many cases of diversified management did not differ from the reference scenarios using only BAU, which was not the case when only a selection of the best management regimes were included.

Random allocation of management regimes to stands was also a source of considerable variation. For instance, the reference scenarios, that included only BAU and set-aside, experienced dramatic 
variability (about $\pm 20 \%$ in multispecies habitat availability), with the results depending on how the set-aside stands where chosen. Adequacy between stand characteristics and choice of management is therefore a crucial factor, which can be optimized by careful planning (Triviño et al. 2017; Eyvindson et al. 2018, 2021). From our results, it is clear that blind management diversification is far from optimal, and careful landscape planning can make a huge difference. For a better benefit for biodiversity, management regimes could be chosen according to site characteristics and expected related natural dynamics (Angelstam 1998; Kuuluvainen 2002), and current stand conditions, particularly stand age. How to best allocate alternative management regimes according to initial stand characteristics would require further investigations.

Our results highlight the economic cost of management diversification. Increasing set-aside resulted in dramatic decrease in forest economic value, while being very effective to increase habitat availability for the biodiversity indicator species. There was, however, a minimal economic cost $(<1 \%)$ of management diversification with the 12 alternative management regimes, while diversification using a subset of five alternative management regimes led to $7-10 \%$ decrease in economic value. Relative to multispecies habitat availability, it seems that diversification with 12 management regimes can be more cost-effective. However, in view of the great uncertainty associated with these scenarios it seems safer, although more costly, to select the best management regimes before implementing management diversification. In addition, at a constant level of set aside, considerable habitat availability gains can be obtained using the combination of the best alternative management, but this incurs a higher economic cost. In some regions, where intact forests are available for conversion into managed forest (e.g. North America, Russia), management diversification could lead to expansion of managed forest to compensate for the resulting reduced net income. However, this would incur higher operational costs related to road construction, which were not included in here as they are usually not needed in Finland.

The tested scenarios represented different levels of set-aside and management diversification, and it seems that management diversification may be more economically cost-efficient in providing diverse forest habitats than set-aside. However, it should be noted that these values are predicted average values and may differ greatly from optimal solutions. Importantly, many species require unmanaged, old-growth forests (Niemelä 1999; Bengtsson et al. 2000). Hence, some proportion of set-aside is still an important conservation tool and management diversification should be seen as an effective supplement (Gustafsson et al. 2010; Hanski 2011). An additional argument in favour to keep a certain proportion of set-aside is the variability in habitat availability over time, as we found that the introduction of set-aside can prevent habitat availability to drop close to zero. Landscape dynamics may lead to period of time with very limited amount of habitat (i.e. bottleneck), increasing extinction risk for related species (Roberge et al. 2015, 2018). Sparing a certain amount of unmanaged forest can act as refuge and safeguard biodiversity shall the manage forest experiences a concentration of harvests.

The reason for an increased multispecies habitat availability in diversified scenarios is a complementarity of alternative management regimes in providing habitats for forest species with various habitat requirements. The comparison of management regimes in providing suitable habitats for the six biodiversity indicator species on average, showed the superiority of set-aside over alternative management regimes. However, set-aside was not the optimal management regimes for all species and the maximum habitat availability for each indicator species was obtain with different management regimes, indicating their complementarity in providing diversified habitats. One potential limitation, is that our habitat suitability models relied exclusively on local stand-level characteristics, ignoring spatial interactions. In landscape highly dominated by forest (as is the case here), edge effect and habitat complementation between forest and other habitats is minimal. To address this, one option would be to account for distances to clear-cuts when evaluating the suitability of stands, requiring landscape studies linking harvesting patterns to species presence, which are not common (but see e.g. Barbaro et al. 2007 or Kirkpatrick et al. 2017). In addition, the focal species are relatively good dispersers, thus, habitat availability is likely the driving force of population persistence and fragmentation is less of an issue. Alternatively, an additional step to habitat modelling would be to assess how habitat 
patches are connected in space and time (Martensen et al. 2017). Therefore, we believe spatially explicit models will not have a large impact on the observed patterns, however spatial configuration of management diversity effects on biodiversity is worth considering in the future.

On average the best management regimes that supported multispecies habitat availability were, in addition to set-aside, those combining longer rotation periods, absence of thinnings, and continuous cover forestry with delayed harvest. This combination of management regimes includes the best management regimes of each biodiversity indicator species, ensuring the simultaneous availability of habitats for different groups of species at landscape level. It should be noted green tree retention was poorly performing in our study, being only slightly better than the business-as-usual management. Previous studies showed the benefit of tree retention for biodiversity, but usually in comparison to conventional clearcutting, not to other management alternatives (e.g. Fedrowitz et al. 2014). This might be because the business-as-usual management also included, following the Finnish legislation, some tree retention (10 trees/ha in BAU vs. 30 trees/ha in BAU_wGTR, see Table 1), or because we did not included true openhabitat specialist dependent on dry sun-exposed conditions (Siitonen 2001). Increased level of tree retention may not be the best taken alone but could complement other alternatives when applied simultaneously at stand level with for instance extended rotation (Felton et al. 2017), absence of thinnings, or continuous cover forestry (Gustafsson et al. 2012; Mönkkönen et al. 2018); combinations not tested here (Table 1).

Habitat heterogeneity could be further promoted by using additional alternative management regimes not included in the present study. Indeed, the alternative management regimes we used mostly emulate intermediate and late-successional habitats, while, for a complete coverage of biodiversity, early successional habitats should be restored as well (Kuuluvainen and Grenfell 2012). This could be achieved by introducing the whole gradient of partial cut/tree retention that would benefit both open- and closed-canopy species (Kebli et al. 2012; Pinzon et al. 2016). Deadwood enrichment using a diversity of tree species, and various topographic and soil conditions for created deadwood is expected to further increase habitat heterogeneity and species beta diversity (Gossner et al. 2013, 2016; Johansson et al. 2017). Finally, prescribed burning is the only alternative management able to produce burned deadwood substrates that are crucial for exclusive pyrophylous saproxylic organisms. Controlled low-intensity burning can increase total species richness and generate unique species composition of beetles communities (Toivanen and Kotiaho 2007; Hjältén et al. 2010; Heikkala et al. 2016).

\section{Conclusions}

The present study showed that management diversification can be a cost-efficient way to simultaneously increase habitat availability for a diversity of indicator and umbrella species in production boreal forests. A combination of various management regimes would generate heterogeneous mosaic of forest covers, thus promoting species co-existence at landscape scale (beta diversity). Given the similarity in the habitat homogenization process caused by forestry operations, this conclusion is most likely valid in temperate zones as well. However, to reach the full benefits of management diversification careful landscape level planning is needed. The alternative management regimes we tested here, e.g. longer rotation (Roberge et al. 2016) and continuous cover forestry (Peura et al. 2018; Eyvindson et al. 2021), have been shown to promote non-timber ecosystem services. Thus, management diversity would not only contribute to biodiversity conservation but also provide multiple benefits for society, including carbon sequestration, non-timber production and recreational values.

Management diversity should also create diverse forest structures and dynamics which should increase forest adaptability to an uncertain future (Kuuluvainen and Grenfell 2012). Indeed, if human-induced disturbances resemble the natural ones, it should support forest functioning and resilience to atypical disturbance events generated by, for instance, climate change. In this respect, management diversification aligns with the general objective of emulating natural disturbances and the current understanding of disturbance-succession dynamics.

Acknowledgements RD was supported by a postdoctoral fellowship from the Kone Foundation. The authors thanks all 
members of the Boreal Ecosystem Research Group for the supportive environment and discussions. The authors thank four anonymous reviewers for their constructive feedbacks on earlier version of the manuscript.

Funding Open Access funding provided by University of Jyväskylä (JYU). This work received support from Koneen Säätiö.

Open Access This article is licensed under a Creative Commons Attribution 4.0 International License, which permits use, sharing, adaptation, distribution and reproduction in any medium or format, as long as you give appropriate credit to the original author(s) and the source, provide a link to the Creative Commons licence, and indicate if changes were made. The images or other third party material in this article are included in the article's Creative Commons licence, unless indicated otherwise in a credit line to the material. If material is not included in the article's Creative Commons licence and your intended use is not permitted by statutory regulation or exceeds the permitted use, you will need to obtain permission directly from the copyright holder. To view a copy of this licence, visit http://creativecommons.org/licenses/by/4.0/.

\section{References}

Äijälä O, Koistinen A, Sved J, Vanhatalo K, Väisänen P (2014) Metsänhoidon suositukset. [The good practice guidance to forestry]. Metsäkustannus Oy, Forestry Development CentreTapio, Helsinki (In Finnish)

Angelstam P (1992) Conservation of communities-the importance of edges, surroundings and landscape mosaic structure. In: Hansson L (ed) The ecological principles of nature conservation: applications in temperate and boreal environments. Springer Verlag, New York, pp 9-70

Angelstam PK (1998) Maintaining and restoring biodiversity in European boreal forests by developing natural disturbance regimes. J Veg Sci 9:593-602

Angelstam P, Boutin S, Schmiegelow F et al (2004) Targets for Boreal forest biodiversity conservation: a rationale for macroecological research and adaptive management. Ecol Bull 51:487-509

Barbaro L, Rossi J-P, Vetillard F et al (2007) The spatial distribution of birds and carabid beetles in pine plantation forests: the role of landscape composition and structure. J Biogeogr 34:652-664

Bengtsson J, Nilsson SG, Franc A, Menozzi P (2000) Biodiversity, disturbances, ecosystem function and management of European forests. For Ecol Manag 132:39-50

Bouget C, Duelli P (2004) The effects of windthrow on forest insect communities: a literature review. Biol Conserv 118:281-299

Bouget C, Larrieu L, Brin A (2014) Key features for saproxylic beetle diversity derived from rapid habitat assessment in temperate forests. Ecol Ind 36:656-664
Eyvindson K, Duflot R, Triviño M et al (2021) High boreal forest multifunctionality requires continuous cover forestry as a dominant management. Land Use Policy 100:104918

Eyvindson K, Repo A, Mönkkönen M (2018) Mitigating forest biodiversity and ecosystem service losses in the era of biobased economy. For Policy Econ 92:119-127

Fedrowitz K, Koricheva J, Baker SC et al (2014) Can retention forestry help conserve biodiversity? A meta-analysis. J Appl Ecol 51:1669-1679

Felton A, Sonesson J, Nilsson U et al (2017) Varying rotation lengths in northern production forests: implications for habitats provided by retention and production trees. Ambio 46:324-334

Gossner MM, Lachat T, Brunet J et al (2013) Current near-tonature forest management effects on functional trait composition of saproxylic beetles in beech forests. Conserv Biol 27:605-614

Gossner MM, Wende B, Levick S et al (2016) Deadwood enrichment in European forests-which tree species should be used to promote saproxylic beetle diversity? Biol Conserv 201:92-102

Gustafsson L, Baker SC, Bauhus J et al (2012) Retention forestry to maintain multifunctional forests: a world perspective. Bioscience 62:633-645

Gustafsson L, Kouki J, Sverdrup-Thygeson A (2010) Tree retention as a conservation measure in clear-cut forests of Northern Europe: a review of ecological consequences. Scand J For Res 25:295-308

Hanski I (2011) Habitat loss, the dynamics of biodiversity, and a perspective on conservation. Ambio 40:248-255

Hanski IK, Mönkkönen M, Reunanen P, Stevens P (2000) Ecology of the Eurasian flying squirrel (Pteromys volans) in Finland. In: Goldingay R, Scheibe J (eds) Biology of Gliding Mammals. Filander Verlag GmbH, Fürth, Germany, pp 67-86

Heikkala O, Martikainen P, Kouki J (2016) Decadal effects of emulating natural disturbances in forest management on saproxylic beetle assemblages. Biol Conserv 194:39-47

Hjältén J, Gibb H, Ball JP (2010) How will low-intensity burning after clear-felling affect mid-boreal insect assemblages? Basic Appl Ecol 11:363-372

Hokkanen H, Törmälä T, Vuorinen H (1982) Decline of the flying squirrel Pteromys volans 1. populations in Finland. Biol Conserv 23:273-284

Hurme E, Mönkkönen M, Sippola A-L et al (2008) Role of the Siberian flying squirrel as an umbrella species for biodiversity in Northern Boreal forests. Ecol Ind 8:246-255

Hyvärinen E, Juslén AK, Kemppainen E et al (2019) Suomen lajien uhanalaisuus 2019-Punainen kirja: the 2019 red list of Finnish species. Ympäristöministeriö \& Suomen ympäristökeskus, Helsinki

Jansson G, Angelstam P (1999) Threshold levels of habitat composition for the presence of the long-tailed tit (Aegithalos caudatus) in a boreal landscape. Landsc Ecol 14:283-290

Johansson P-O, Kriström B (2012) The economics of evaluating water projects: hydroelectricity versus other uses. Springer Science \& Business Media, Berlin

Johansson T, Gibb H, Hjältén J, Dynesius M (2017) Soil humidity, potential solar radiation and altitude affect 
boreal beetle assemblages in dead wood. Biol Conserv 209:107-118

Juutilainen K, Mönkkönen M, Kotiranta H, Halme P (2014) The effects of forest management on wood-inhabiting fungi occupying dead wood of different diameter fractions. For Ecol Manag 313:283-291

Kebli H, Brais S, Kernaghan G, Drouin P (2012) Impact of harvesting intensity on wood-inhabiting fungi in boreal aspen forests of Eastern Canada. For Ecol Manag 279:45-54

Kirkpatrick L, Bailey S, Park KJ (2017) Negative impacts of felling in exotic spruce plantations on moth diversity mitigated by remnants of deciduous tree cover. For Ecol Manag 404:306-315

Kuuluvainen T (2002) Natural variability of forests as a reference for restoring and managing biological diversity in boreal Fennoscandia. Silva Fenn 36:97-125

Kuuluvainen T (2009) Forest management and biodiversity conservation based on natural ecosystem dynamics in Northern Europe: the complexity challenge. Ambio 38:309-315

Kuuluvainen T, Gauthier S (2018) Young and old forest in the boreal: critical stages of ecosystem dynamics and management under global change. For Ecosyst 5:26

Kuuluvainen T, Grenfell R (2012) Natural disturbance emulation in boreal forest ecosystem management-theories, strategies, and a comparison with conventional even-aged management. Can J For Res 42:1185-1203

Larrieu L, Cabanettes A, Gouix N et al (2017) Development over time of the tree-related microhabitat profile: the case of lowland beech-oak coppice-with-standards set-aside stands in France. Eur J For Res 136:37-49

Martensen AC, Saura S, Fortin M-J (2017) Spatio-temporal connectivity: assessing the amount of reachable habitat in dynamic landscapes. Methods Ecol Evol 8:1253-1264

Miettinen J (2009) Capercaillie (Tetrao urogallus L.) habitats in managed Finnish forests-the current status, threats and possibilities. Diss For. https://doi.org/10.14214/df.90

Mönkkönen M, Burgas D, Eyvindson K et al (2018) Solving conflicts among conservation, economic, and social objectives in boreal production forest landscapes: Fennoscandian perspectives. In: Perera AH, Peterson U, Pastur GM, Iverson LR et al (eds) Ecosystem services from forest landscapes: broadscale considerations. Springer International Publishing, Cham, pp 169-219

Mönkkönen M, Juutinen A, Mazziotta A et al (2014) Spatially dynamic forest management to sustain biodiversity and economic returns. J Environ Manag 134:80-89

Niemelä $J$ (1999) Management in relation to disturbance in the boreal forest. For Ecol Manag 115:127-134

Nolet P, Kneeshaw D, Messier C, Béland M (2018) Comparing the effects of even- and uneven-aged silviculture on ecological diversity and processes: a review. Ecol Evol $8: 1217-1226$

Odion DC, Sarr DA (2007) Managing disturbance regimes to maintain biological diversity in forested ecosystems of the Pacific Northwest. For Ecol Manag 246:57-65

Pakkala T (2012) Spatial ecology of breeding birds in forest landscapes: an indicator species approach. Diss For 2012(151): 1
Pakkala T, Hanski I, Tomppo E (2002) Spatial ecology of the three-toed woodpecker in managed forest landscapes. Silva Fenn. https://doi.org/10.14214/sf.563

Pakkala T, Pellikka J, Lindén H (2003) Capercaillie Tetrao urogallus - a good candidate for an umbrella species in taiga forests. Wbio 9:309-316

Peura M, Burgas D, Eyvindson K et al (2018) Continuous cover forestry is a cost-efficient tool to increase multifunctionality of boreal production forests in Fennoscandia. Biol Conserv 217:104-112

Pinzon J, Spence JR, Langor DW, Shorthouse DP (2016) Tenyear responses of ground-dwelling spiders to retention harvest in the boreal forest. Ecol Appl 26:2579-2597

Pukkala T, von Gadow K (2012) Continuous Cover Forestry. Springer, Dordrecht

Rasinmäki J, Mäkinen A, Kalliovirta J (2009) SIMO: an adaptable simulation framework for multiscale forest resource data. Comput Electron Agric 66:76-84

Redon M, Luque S, Gosselin F, Cordonnier T (2014) Is generalisation of uneven-aged management in mountain forests the key to improve biodiversity conservation within forest landscape mosaics? Ann For Sci 71:751-760

Roberge J-M, Angelstam P (2006) Indicator species among resident forest birds-a\&nbsp;cross-regional evaluation in northern Europe. Biol Conserv 130:134-147

Roberge J-M, Lämås T, Lundmark T et al (2015) Relative contributions of set-asides and tree retention to the longterm availability of key forest biodiversity structures at the landscape scale. J Environ Manag 154:284-292

Roberge J-M, Laudon H, Björkman C et al (2016) Socio-ecological implications of modifying rotation lengths in forestry. Ambio 45(Suppl 2):109-123

Roberge J-M, Öhman K, Lämås T et al (2018) Modified forest rotation lengths: long-term effects on landscape-scale habitat availability for specialized species. J Environ Manag 210:1-9

Schall P, Gossner MM, Heinrichs S et al (2018) The impact of even-aged and uneven-aged forest management on regional biodiversity of multiple taxa in European beech forests. J Appl Ecol 55:267-278

Schütz J-P, Saniga M, Diaci J, Vrška T (2016) Comparing closeto-naturesilviculture with processes in pristine forests: lessons from Central Europe. Ann For Sci 73:911-921

Siitonen J (2001) Forest management, coarse woody debris and saproxylic organisms: Fennoscandian boreal forests as an example. Ecol Bull 49:11-41

Tikkanen O-P, Matero J, Mönkkönen M et al (2012) To thin or not to thin: bio-economic analysis of two alternative practices to increase amount of coarse woody debris in managed forests. Eur J For Res 131:1411-1422

Toivanen T, Kotiaho JS (2007) Mimicking natural disturbances of boreal forests: the effects of controlled burning and creating dead wood on beetle diversity. Biodivers Conserv 16:3193-3211

Triviño M, Pohjanmies T, Mazziotta A et al (2017) Optimizing management to enhance multifunctionality in a boreal forest landscape. J Appl Ecol 54:61-70

Tscharntke T, Tylianakis JM, Rand TA et al (2012) Landscape moderation of biodiversity patterns and processes-eight hypotheses. Biol Rev 87:661-685 
White JW, Rassweiler A, Samhouri JF et al (2014) Ecologists should not use statistical significance tests to interpret simulation model results. Oikos 123:385-388
Publisher's Note Springer Nature remains neutral with regard to jurisdictional claims in published maps and institutional affiliations. 